\title{
Effect of Plasma-Polymerized Layer Formed on a Surface of Titanium Dioxide Particle on Its Photocatalytic Activity*
}

\author{
Kenji YAMADA*1, Naoko IWASAWA*1, Tatsuhiko SONODA*1, Hirokazu YAMANE*1, \\ Shigenori MATSUSHIMA*1 and Hiroyuki NAKAMURA*2 \\ ${ }^{*}$ Department of Materials Science and Chemical Engineering, Kitakyushu National College of Technology, Kitakyushu, Fukuoka 802-0985, Japan \\ ${ }^{*}$ Department of Integrated Arts and Science Kitakyushu National College of Technology, Kitakyushu, Fukuoka 802-0985, Japan
}

(Received January 4, 2007, Accepted August 4, 2007)

If $\mathrm{TiO}_{2}$ particles are used as components of paint without any surface modification, binding resin of the paint will be easily decomposed by the photocatalytic activity of the particles. In this work, plasma polymerization of octamethylcyclotetrasiloxane as a siloxane monomer is tried to form thin layer stable to the photocatalytic activity on the surface of $\mathrm{TiO}_{2}$ particles. The plasma-polymerized layer containing $\mathrm{Si}-\mathrm{O}$ and $\mathrm{Si}-\mathrm{C}$ bonds is formed on the surface of the particles and shows stability to the photocatalytic activity of $\mathrm{TiO}_{2}$. The particles surface-modified with the plasma polymerization exhibit visiblelight activity. The visible-light activity is originated from carbon doping which brings about in the particles during the plasma polymerization, and is thermally stable to be maintained after annealing at $673 \mathrm{~K}$.

\section{Introduction}

Visible-light-active (vis-active) $\mathrm{TiO}_{2}$ has been prepared by various methods ${ }^{1-9)}$. According to Takeuchi et al.1) and Ihara et al. ${ }^{2}$, the reduction of $\mathrm{TiO}_{2}$ by hydrogen plasma treatment with elevated temperatures created a new absorption band in the visible-light region and showed photocatalytic activity in this region.

Vis-active $\mathrm{TiO}_{2}$ films and powders were prepared by a nitrogen-doping ${ }^{3-6)}$. According to Asahi et al. ${ }^{3)}$, $\mathrm{TiO}_{2-x} \mathrm{~N}_{\mathrm{x}}$ films were prepared by the sputtering of $\mathrm{TiO}_{2}$ target in $\mathrm{N}_{2}(40 \%) /$ Ar gas mixture, and $\mathrm{TiO}_{2-x} \mathrm{~N}_{\mathrm{x}}$ powders were prepared by the treatment of anatase $\mathrm{TiO}_{2}$ powders in $\mathrm{NH}_{3}(67 \%) / \mathrm{Ar}$ atmosphere at $873 \mathrm{~K}$ for $3 \mathrm{~h}$. Nitrogen-doped $\mathrm{TiO}_{2}$ powders were also prepared by the oxidative annealing of TiN powders for $90 \mathrm{~min}$ in an oxygen gas flow at $823 \mathrm{~K}^{4)}$. According to Irie et al. ${ }^{5}$, $\mathrm{TiO}_{2-x} \mathrm{~N}_{\mathrm{x}}$ powders were prepared by the annealing of anatase $\mathrm{TiO}_{2}$ powders under $\mathrm{NH}_{3}$ flow at 823, 848, and $873 \mathrm{~K}$ for $3 \mathrm{~h}$. Nitrogen-doped $\mathrm{TiO}_{2}$ particles were also prepared by a series of argon and nitrogen plasma treatment ${ }^{6}$. The $\mathrm{TiO}_{2}$ particles having $\mathrm{Ti}-\mathrm{N}$ bonds formed by substitutional nitrogen-doping showed photocatalytic activities under visible-light irradiation (vis irradiation).

Sulfur-doped $\mathrm{TiO}_{2}$ powders into which the oxidation state of the $\mathrm{S}$ atoms is incorporated showed visible light activity (vis activity) ${ }^{7)}$. Carbon-doped $\mathrm{TiO}_{2}$ powders showing vis activity were fabricated by oxidative annealing of $\mathrm{TiC}$, in which the doped carbons were located at oxygen sites ${ }^{8}$. Carbonate-species-doped $\mathrm{TiO}_{2}$ showed also vis activity ${ }^{9}$.

For the improvement of the thermal stability of the photocatalytic activity in $\mathrm{TiO}_{2}$ powders, silica-modified

* Presented as an invited talk in the International Symposium on Science and Engineering of Interface Engineering, August 5-7, 2006, Hamamatsu, JAPAN
$\mathrm{TiO}_{2}$ powders were prepared by the glycothermal method ${ }^{10)}$. In the silica-modified $\mathrm{TiO}_{2}$ powders, the presence of $\mathrm{Si}$ in the $\mathrm{TiO}_{2}$ lattice seems to contribute to the deceleration of the grain growth of anatase and the suppression of anatase-rutile transformation. The silicamodified $\mathrm{TiO}_{2}$ powders after nitrogen doping by a treatment at $873 \mathrm{~K}$ with $\mathrm{NH}_{3}$ exhibited a high photocatalytic activity under vis irradiation ${ }^{11)}$.

If $\mathrm{TiO}_{2}$ particles are used as fillers in the paint, binding resin of the paint will be decomposed by photocatalytic activity of the particles under UV irradiation. In this work, a thin layer that is stable to the photocatalytic activity is tried to be formed on the surface of $\mathrm{TiO}_{2}$ particles by plasma polymerization of a siloxane monomer to depress the decomposition of the binding resin. Since the inherent photocatalytic activity of the particles will be decreased by the formation of the plasma-polymerized layer, the layer should be optimized to depress both the decomposition of the binding resin and the decrease in the photocatalytic activity. Relationship between structure of the thin layer and photocatalytic properties in $\mathrm{TiO}_{2}$ particles is investigated in this work. Furthermore, possibilities of plasma doping with constituent atoms of the siloxane monomer and an emergence of vis activity are also investigated for the plasma-polymerized $\mathrm{TiO}_{2}$ particles before and after annealing.

\section{Experimental}

\subsection{Plasma polymerization}

Anatase-type $\mathrm{TiO}_{2}$ particles (ST01, Ishihara Sangyo Co., Osaka, Japan) were used in this work. The average diameter of the primary particles is about $7 \mathrm{~nm}$. A round-bottomed flask-type reactor was used for the treatment of the particles with inductively coupled plasma at $13.56 \mathrm{MHz}$. The particles introduced into the reactor were evacuated for 1 day with a vacuum system and then were pretreated with argon plasma at $100 \mathrm{~W}$ at argon pressure of $13 \mathrm{~Pa}$ for $60 \mathrm{~min}$. The reactor was rotat- 
ed at $32 \mathrm{rpm}$ during the plasma treatment for homogeneous treatment of the particles. Then the particles were plasma-polymerized with octamethylcyclotetrasiloxane as a monomer. The discharge power was $30 \mathrm{~W}$, the discharge time was in the range of 10 to $50 \mathrm{~min}$, and the monomer pressure was $11 \mathrm{~Pa}$. The reactor was also rotated at $32 \mathrm{rpm}$ during the plasma polymerization.

2.2 Surface analyses of plasma-polymerized $\mathrm{TiO}_{2}$ particles

For the confirmation of the formation of the plasmapolymerized layer on the surface of the $\mathrm{TiO}_{2}$ particles, surface area and pore distribution of the particles were measured before and after plasma polymerization with Thermo Quest Sorptmatic 1990 (Thermo Quest Co., Italy). The $\mathrm{TiO}_{2}$ particles had been heated at $423 \mathrm{~K}$ for $10 \mathrm{~h}$ to remove water molecules adsorbed on the surface of the particles before the measurement.

An infrared spectrum of the surface of the plasmapolymerized $\mathrm{TiO}_{2}$ particles was measured with Magna 550 Fourier transform infrared spectroscopy (Nicolet Analytical Instruments, Madison, WI) equipped with Barnes analytical diffuse reflectance accessory to identify the chemical structure of the plasma-polymerized layer. X-ray photoelectron spectroscopy (XPS) measurement was carried out with Shimadzu ESCA750 X-ray photoelectron spectroscopy (Shimadzu Co., Kyoto, Japan) to clarify a change in the surface structure of the $\mathrm{TiO}_{2}$ particles after the plasma polymerization. The infrared spectroscopy and XPS measurements were also carried out to clarify the effect of the irradiation of a $150 \mathrm{~W} \mathrm{Xe}$ lamp on the surface state of the plasma-polymerized $\mathrm{TiO}_{2}$ particles.

$\mathrm{X}$-ray diffraction (XRD) intensity curves of the particles before and after the plasma polymerization were measured with Rigaku Rint 1200 X-ray diffractometer (Rigaku Denki Co., Tokyo, Japan) to clarify the crystal structure of the $\mathrm{TiO}_{2}$ particles after the plasma polymerization.

\subsection{Thermal stability of plasma-polymerized $\mathrm{TiO}_{2}$ par- ticles}

The thermal degradation behavior of the plasmapolymerized $\mathrm{TiO}_{2}$ particles was measured at a heating rate of $5 \mathrm{Kmin}^{-1}$ at a dry air-flow rate of $10 \mathrm{mLmin}^{-1}$ with a TG/DTA200 system (Seiko Denshikogyo Co., Chiba, Japan). The weight of the sample was $10 \mathrm{mg}$. The plasma-polymerized $\mathrm{TiO}_{2}$ particles were annealed in air at $673 \mathrm{~K}$ for $60 \mathrm{~min}$ and a change in the surface structure of the particles with annealing was analyzed with infrared spectroscopy and XPS.

\subsection{Photocatalytic properties of plasma-polymerized $\mathrm{TiO}_{2}$ particles}

UV-vis diffuse reflectance spectra of the plasmapolymerized $\mathrm{TiO}_{2}$ particles were measured with JASCO V-500 UV-vis spectrophotometer (JASCO International Co., Tokyo, Japan) equipped with integral-sphere attachment to clarify a change in light absorbance behavior after the plasma polymerization. The plasmapolymerized particles were immersed into $1 \mathrm{mM}$ methylene blue of water solution for 1 day in the dark to adsorb methylene blue molecules. The particles were washed with pure water and then dried in vacuo at $303 \mathrm{~K}$ for $1 \mathrm{~h}$.

A $150 \mathrm{~W}$ Xe lamp as the light source and two cutoff filters for UV region (wavelength $<420 \mathrm{~nm}$ ) and IR region (wavelength $>750 \mathrm{~nm}$ ) were used to obtain the visible light. Methylene blue adsorbed on the surface of the $\mathrm{TiO}_{2}$ particles was irradiated with the visible light for $3 \mathrm{~h}$. A decrease in absorbance at $664 \mathrm{~nm}$ of methylene blue was measured for the evaluation of the photocatalytic properties of plasma-polymerized $\mathrm{TiO}_{2}$ particles.

\section{Results and Discussion}

\subsection{Surface analyses of plasma-polymerized $\mathrm{TiO}_{2}$}

Figure 1 shows pore distributions of $\mathrm{TiO}_{2}$ particles before and after plasma polymerization. The maximum distribution was around $1.5 \mathrm{~nm}$ before the plasma polymerization, whereas a slight broadening to the smaller pore size took place after the plasma polymerization. The pores could be formed among the primary particles or the secondary ones which are aggregated one another. Specific surface areas before and after the plasma polymerization were 322.6 and $245.3 \mathrm{~m}^{2} \mathrm{~g}^{-1}$, respectively. These results mean that the pore size is decreased by the plasma-polymerized layer formed on the surface of the aggregated particles in the pores.

Figure 2 shows infrared spectra of the surface of $\mathrm{TiO}_{2}$ particles before and after plasma polymerization. There are several absorption bands newly observed after the plasma polymerization. Absorption bands around 1120 and $1270 \mathrm{~cm}^{-1}$ are assigned to $\mathrm{C}-\mathrm{O}$ stretching of ester group, while those around 775 and $1250 \mathrm{~cm}^{-1}$ to $\mathrm{Si}-\mathrm{CH}_{3}$
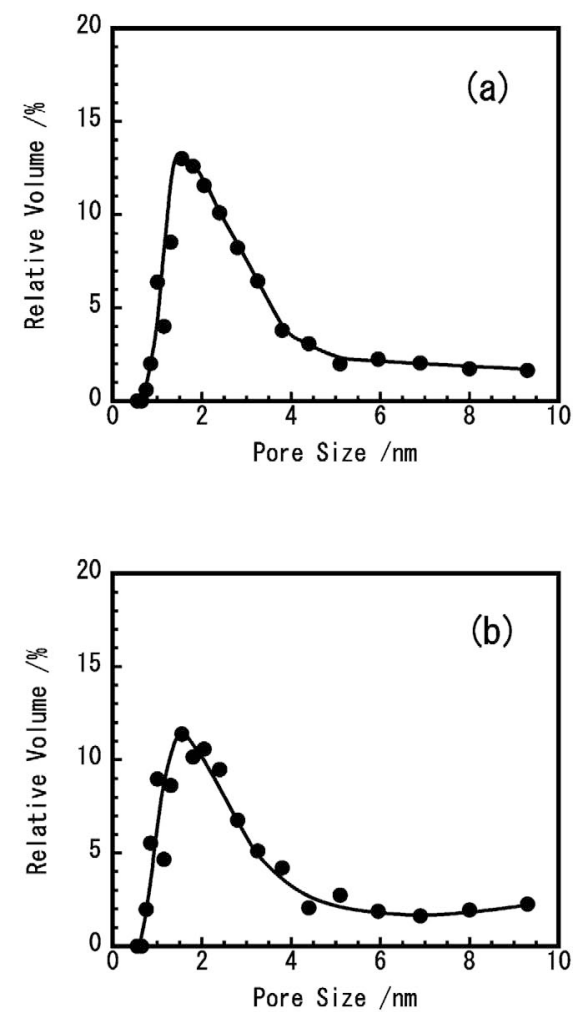

Fig. 1 Pore distributions of $\mathrm{TiO}_{2}$ particles (a) before and (b) after plasma polymerization. Plasma polymerization time, 20 $\min$. 
stretching and that around $1650 \mathrm{~cm}^{-1}$ to $\mathrm{C}=\mathrm{O}$ stretching of ester group. Therefore it becomes apparent that the plasma-polymerized layer is composed of fragments that are not necessarily originated from the monomer.

Figure 3 shows $\mathrm{Si} / \mathrm{Ti}$ atomic ratio at the surface of the plasma-polymerized $\mathrm{TiO}_{2}$ particles as a function of plasma polymerization time. The atomic ratio is evaluated by using XPS peak-strength ratio, $\mathrm{Si}_{2 \mathrm{p}} / \mathrm{Ti}_{2 \mathrm{p}}$. The ratio was increased with increasing polymerization time up to around $35 \mathrm{~min}$ and then was decreased. On the other hand, $\mathrm{C} / \mathrm{Ti}$ atomic ratio was little changed in the range of plasma polymerization time. The plasma polymerization would preferentially take place up to around 35 min, whereas abrasion or peeling off of the plasmapolymerized layer would preferentially take place after that. The Gibbs free energy of an addition polymerization contains enthalpy and entropy terms, that is, $\Delta G=$ $\Delta H-T \Delta S$. When the reaction temperature is raised above the ceiling temperature of the polymerization, $\mathrm{T}_{\mathrm{c}}$, polymer formation cannot proceed spontaneously ${ }^{12}$. The ceiling temperature of polymerization in gas phase would be much lower than that in the liquid phase. Since the plasma polymerization is exothermic, the temperature of $\mathrm{TiO}_{2}$ particles will be raised with increasing plasma polymerization time. It can therefore be presumed that the temperature of $\mathrm{TiO}_{2}$ particles goes up to over the $\mathrm{T}_{\mathrm{c}}$ at plasma polymerization time of around $35 \mathrm{~min}$.

Figure 4 shows weight reduction of plasma-polymer-

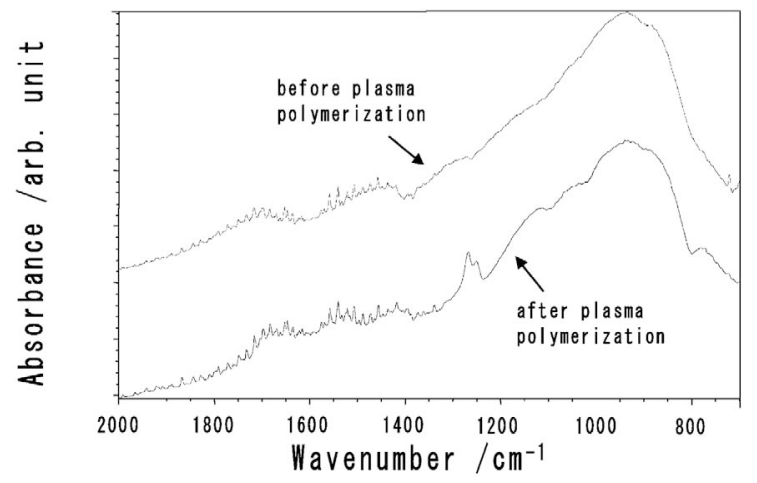

Fig. 2 Infrared spectra of the surface of $\mathrm{TiO}_{2}$ particles before and after plasma polymerization. Plasma polymerization time, $30 \mathrm{~min}$.

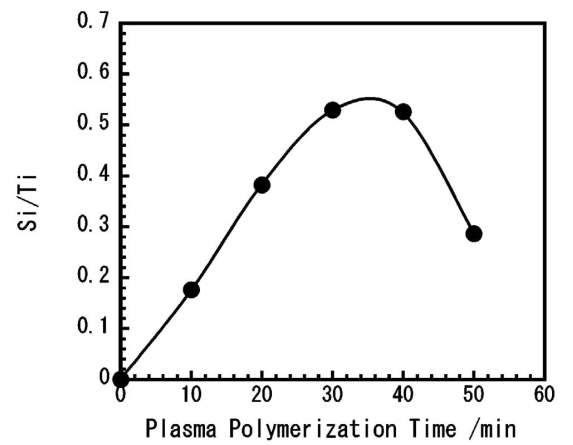

Fig. $3 \mathrm{Si} / \mathrm{Ti}$ atomic ratio on the surface of the plasma-polymerized $\mathrm{TiO}_{2}$ particles as a function of plasma polymerization time. ized $\mathrm{TiO}_{2}$ particles as a function of plasma polymerization time. The weight reduction was measured in the temperature range of 473 to $1273 \mathrm{~K}$ to eliminate low molecular weight molecules such as the monomer adsorbed on the plasma-polymerized layer of the particles. The weight reduction of the particles before the plasma polymerization was $3.9 \%$, since contaminants and water molecules had been adsorbed on the surface. The weight reduction was increased with increasing polymerization time up to around $35 \mathrm{~min}$ and then was decreased, which coincides with $\mathrm{Si} / \mathrm{Ti}$ ratio shown in Figure 3. $\mathrm{Si} / \mathrm{Ti}$ ratio was in the range of 0.2 to 0.24 after the heating. This fact means that thermally stable Si-containing layer is formed on the surface after the heating.

\subsection{Stability of plasma-polymerized layer for $\mathrm{TiO}_{2}$ photocatalytic activity}

Figure 5 shows $\mathrm{Si} / \mathrm{Ti}, \mathrm{C} / \mathrm{Ti}$, and $\mathrm{O} / \mathrm{Ti}$ atomic ratios in plasma-polymerized $\mathrm{TiO}_{2}$ particles as a function of irradiation time with the $\mathrm{Xe}$ lamp. The $\mathrm{Si} / \mathrm{Ti}$ and $\mathrm{C} / \mathrm{Ti}$ ratios were decreased with increasing irradiation time up to $4 \mathrm{~h}$ and then were almost kept constant. The $\mathrm{O} / \mathrm{Ti}$ ratio was decreased in a similar manner as $\mathrm{Si} / \mathrm{Ti}$ and $\mathrm{C} / \mathrm{Ti}$ and then was kept at around 3.3. Therefore it becomes apparent that the plasma polymerized layer stable to the photocatalytic activity of the particles is considerably remained after the irradiation. Figure 6 shows infrared spectra of the surface of plasma-polymerized $\mathrm{TiO}_{2}$ particles before and after the irradiation of the Xe lamp. The absorptions for $\mathrm{Si}-\mathrm{CH}_{3}$ stretching $\left(775\right.$ and $\left.1250 \mathrm{~cm}^{-1}\right)$, $\mathrm{C}-\mathrm{O}$ stretching of ester group (1120 and $1270 \mathrm{~cm}^{-1}$ ), and $\mathrm{Si}-\mathrm{O}-\mathrm{Si}$ and $\mathrm{Si}-\mathrm{O}-\mathrm{C}$ skeletal vibrations (1020-1090 $\mathrm{cm}^{-1}$ ) were distinctly decreased after the irradiation, whereas the broad absorptions for $\mathrm{Si}-\mathrm{C}$ and $\mathrm{Si}-\mathrm{O}$ stretchings $\left(870-900 \mathrm{~cm}^{-1}\right)$ were increased. It is assumed from Figures 5 and 6 that silica- and silicon carbide-like structure mainly composed of $\mathrm{Si}-\mathrm{O}$ and $\mathrm{Si}-\mathrm{C}$ bonds is remained after the irradiation, since the great decrease in absorbance of the functional groups and the broadening of the spectrum take place and $\mathrm{Si}, \mathrm{C}$, and $\mathrm{O}$ atoms are considerably contained in the plasma-polymerized layer after the irradiation.

\subsection{Photocatalytic properties of plasma-polymerized $\mathrm{TiO}_{2}$ particles}

Figure 7 shows absorbance reduction at $664 \mathrm{~nm}$ of methylene-blue-adsorbed $\mathrm{TiO}_{2}$ particles after vis irradia-

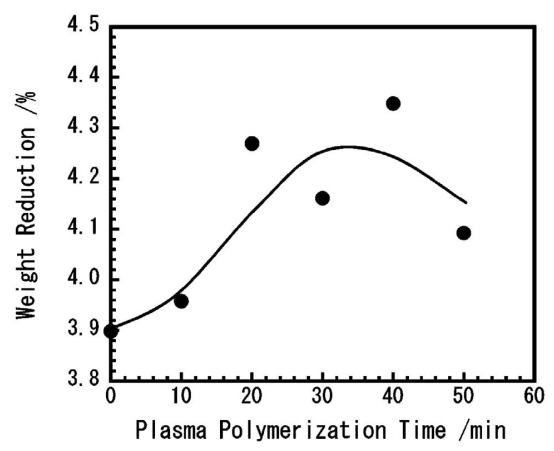

Fig. 4 Weight reduction of plasma-polymerized $\mathrm{TiO}_{2}$ particles as a function of plasma polymerization time. 
tion as a function of plasma polymerization time. A decrease in the absorbance after vis irradiation is divided by the absorbance before the irradiation to evaluate the absorbance reduction in Figure 7. The reduction tended to increase with increasing polymerization time up to around $35 \mathrm{~min}$, and then decreased. Therefore, it becomes apparent that the particles having the plasma-
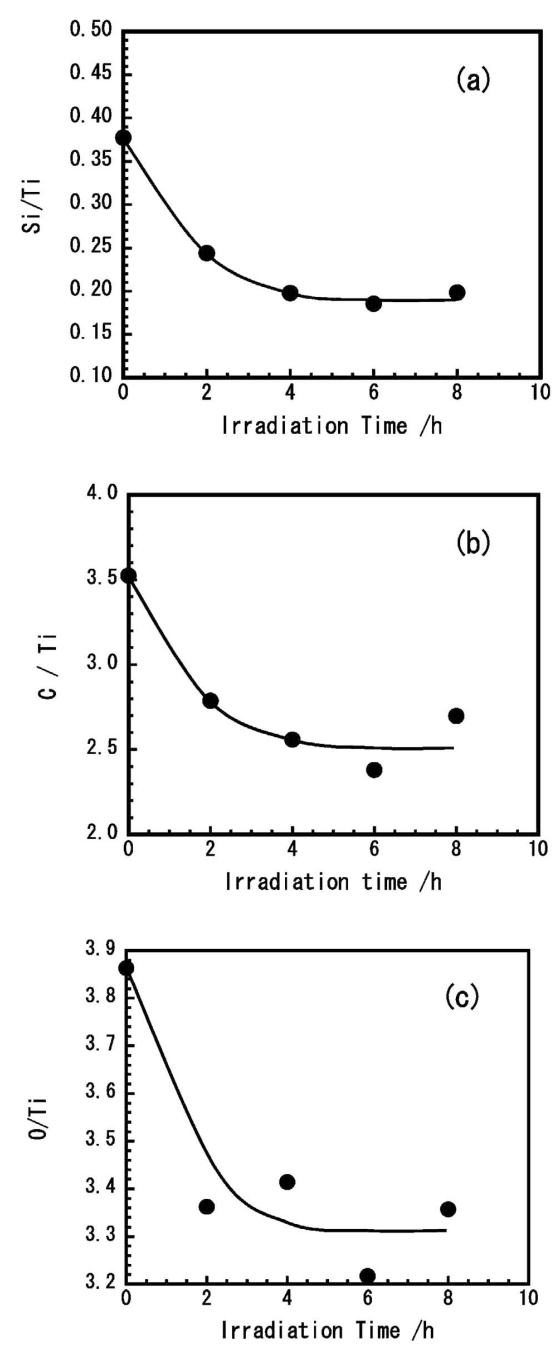

Fig. 5 (a) $\mathrm{Si} / \mathrm{Ti}$, (b) $\mathrm{C} / \mathrm{Ti}$, and (c) $\mathrm{O} / \mathrm{Ti}$ atomic ratios of plasmapolymerized $\mathrm{TiO}_{2}$ particles as a function of irradiation time with $150 \mathrm{~W}$ Xe lamp. Plasma polymerization time, $20 \mathrm{~min}$.

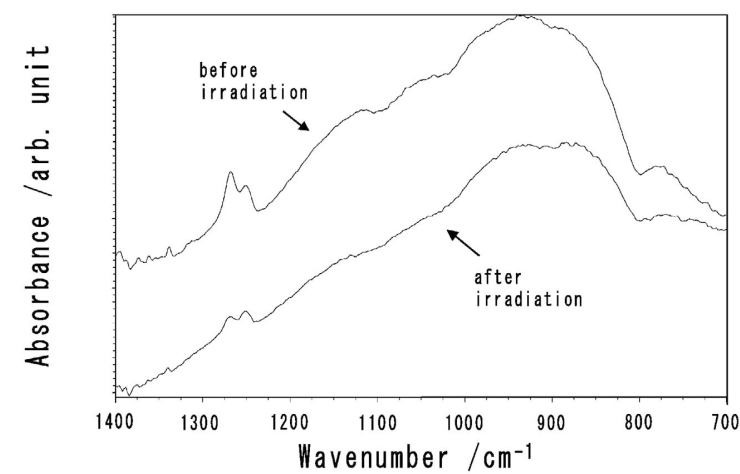

Fig. 6 Infrared spectra of the surface of plasma-polymerized $\mathrm{TiO}_{2}$ particles before and after irradiation of $150 \mathrm{~W}$ Xe lamp. Plasma polymerization time, $30 \mathrm{~min}$; irradiation time, $6 \mathrm{~h}$. polymerized layer show vis activity. Figure 8 shows UV-vis diffuse reflectance spectra of $\mathrm{TiO}_{2}$ particles before and after the plasma polymerization. The particles surface-modified with the plasma polymerization revealed visible light absorption.

A peak assigned to $\mathrm{Ti}-\mathrm{C}$ bonds was observed nearby at $281.8 \mathrm{eV}$ in $\mathrm{C}_{1 \mathrm{~s}}$ XPS spectrum of carbon-doped $\mathrm{TiO}_{2}$ powders ${ }^{8}$. In carbonated species-doped $\mathrm{TiO}_{2}$ powders, $\mathrm{C}_{1 \mathrm{~s}}$ peaks at 284 and $288 \mathrm{eV}$ were observed after calcinations at 673 and $773 \mathrm{~K}^{9)}$. The peak around $284 \mathrm{eV}$ was assigned to carbon adsorbed on the surface of $\mathrm{TiO}_{2}$ as a contaminant (contamination of organic residues on the surface). The latter peak around $288 \mathrm{eV}$ suggests the presence of a carbonate species. Figure 9 shows $C_{1 s}$ XPS spectra of $\mathrm{TiO}_{2}$ particles before and after the plasma polymerization. $\mathrm{C}_{1 \mathrm{~s}}$ peak for a contaminant appeared around $284.5 \mathrm{eV}$ before the plasma polymerization. $\mathrm{C}_{1 \mathrm{~s}}$ peak around $282 \mathrm{eV}$ appeared after the plasma polymerization. Therefore it becomes apparent that Ti-C bonds are formed in the surface area of the particles by the plasma polymerization and carbon doping inducing the formation of $\mathrm{Ti}-\mathrm{C}$ bonds brings about the vis activity. It is assumed that silicon doping during the plasma polymerization is difficult, compared with the carbon doping, since the size of $\mathrm{Si}$ atoms is much larger than that of $\mathrm{C}$ atom. A shoulder around $286 \mathrm{eV}$ is assigned to $\mathrm{C}-\mathrm{O}$ bonds. According to Asahi et al. ${ }^{3)}$, carbon doping

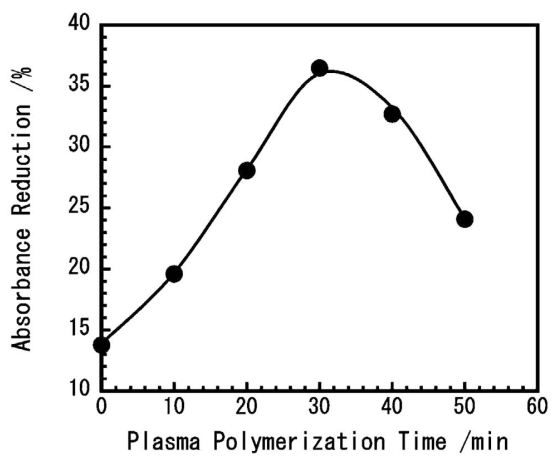

Fig. 7 Absorbance reduction of methylene-blue-adsorbed $\mathrm{TiO}_{2}$ particles as a function of plasma polymerization time.

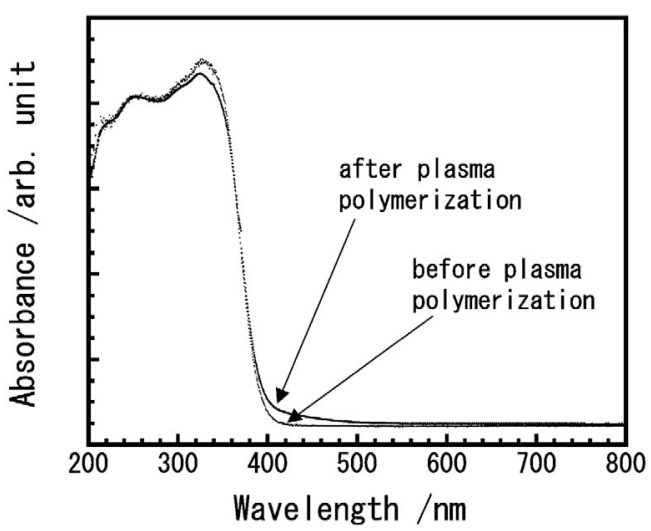

Fig. 8 UV-vis diffuse reflectance spectra of $\mathrm{TiO}_{2}$ particles before and after plasma polymerization. Plasma polymerization time, $30 \mathrm{~min}$. 
produces states in the band gap of $\mathrm{TiO}_{2}$ that absorb visible light. If the states in the gap are overlapped sufficiently with the band states of $\mathrm{TiO}_{2}$, photoexcited carriers, that is, holes and electrons will be transferred to reactive sites at the catalyst surface within their lifetime. Since the carbon-doped $\mathrm{TiO}_{2}$ prepared by the plasma polymerization shows the vis activity, the states due to carbon doping would be overlapped with the valence band state.

It may be originated from decrease in amount of doped carbon that the absorbance reduction of decomposition of methylene blue molecules was decreased above the plasma-polymerization time of around 35 min, as shown in Figure 7. Figure 10 shows $\mathrm{C}(\mathrm{Ti}-\mathrm{C}) / \mathrm{Ti}$ atomic ratio as a function of plasma polymerization time. Since the amount of $\mathrm{C}(\mathrm{Ti}-\mathrm{C}) / \mathrm{Ti}$ in the plasma
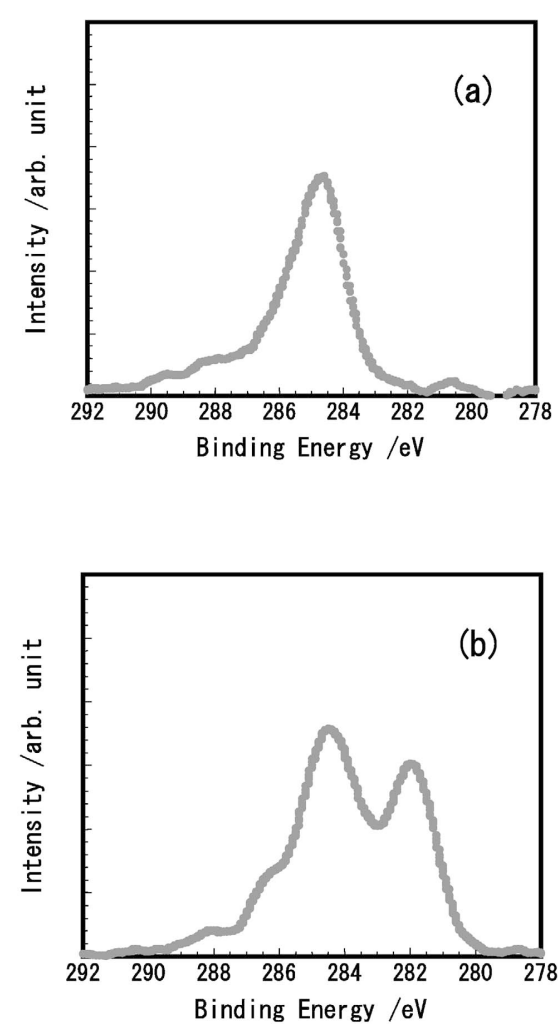

Fig. $9 \mathrm{C}_{1 \mathrm{~s}}$ XPS spectra of $\mathrm{TiO}_{2}$ particles (a) before and (b) after plasma polymerization. Plasma polymerization time, $30 \mathrm{~min}$.

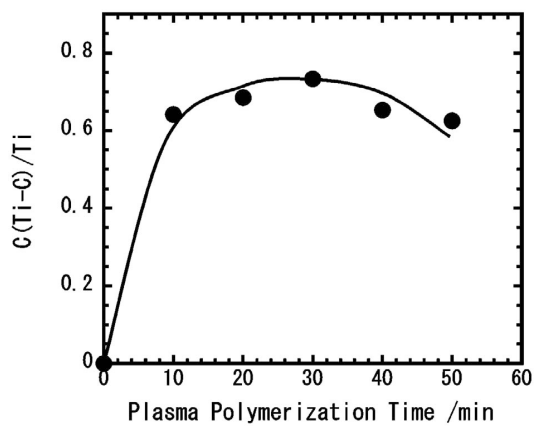

Fig. $10 \mathrm{C}(\mathrm{Ti}-\mathrm{C}) / \mathrm{Ti}$ atomic ratio as a function of plasma polymerization time. $\mathrm{C}(\mathrm{Ti}-\mathrm{C})$ shows the amount of carbons in $\mathrm{Ti}-\mathrm{C}$ bonds. polymerized particles is very large, in the range of 0.62 to 0.74 , it is assumed that the formation of $\mathrm{Ti}-\mathrm{C}$ bonds does not necessarily mean carbon doping into the particles. The significant amount of $\mathrm{Ti}-\mathrm{C}$ bonds is formed in the interface region of the plasma-polymerized layer and $\mathrm{TiO}_{2}$ particles, but the certain extent of carbon doping in the particles is realized to show the vis activity. It becomes apparent from XRD patterns of plasmapolymerized particles that anatase phase remained without collapse and the formation of another crystalline phase was not detected. Therefore it is supported that the certain extent of carbon doping is realized for the vis activity. The amount of $\mathrm{C}(\mathrm{Ti}-\mathrm{C}) / \mathrm{Ti}$ was increased with increasing plasma polymerization time up to around $30 \mathrm{~min}$ and then was decreased. If the amount of $\mathrm{C}(\mathrm{Ti}-\mathrm{C})$ varies in proportion to that of the carbon doping associated with the vis activity, the decrease in the absorbance reduction above $35 \mathrm{~min}$ would be mainly originated from the decrease in $\mathrm{C}(\mathrm{Ti}-\mathrm{C}) / \mathrm{Ti}$.

\subsection{Effect of annealing on photocatalytic property of plasma-polymerized $\mathrm{TiO}_{2}$ particles}

Plasma-polymerized (30 min) $\mathrm{TiO}_{2}$ particles were annealed in air at $673 \mathrm{~K}$ for $60 \mathrm{~min}$. For XPS measurement, all atomic ratios against $\mathrm{Ti}$, that is, $\mathrm{Si} / \mathrm{Ti}, \mathrm{C} / \mathrm{Ti}, \mathrm{O} / \mathrm{Ti}$, and $\mathrm{C}(\mathrm{Ti}-\mathrm{C}) / \mathrm{Ti}$ ratios, decreased $12-16 \%$ after the annealing. Figure 11 shows infrared spectra of the surface of the plasma-polymerized $\mathrm{TiO}_{2}$ particles before and after the annealing. The absorptions for $\mathrm{Si}-\mathrm{CH}_{3}$ stretching (775 and $1250 \mathrm{~cm}^{-1}$ ) almost disappeared and the broad absorption (1020-1090 $\mathrm{cm}^{-1}$ ) for $\mathrm{Si}-\mathrm{O}-\mathrm{Si}$ and $\mathrm{Si}-\mathrm{O}-\mathrm{C}$ skeletal vibrations largely decreased, whereas a broad peak which would be recognized in silica- and silicon carbide-like structure appeared in the range of 700 to 900 $\mathrm{cm}^{-1}$.

In the absorbance measurement of methylene-blue-adsorbed $\mathrm{TiO}_{2}$ particles after plasma polymerization, the absorbance reduction after annealing was diminished to $46 \%$ of that of before annealing and the vis activity was remained. It will be attributable to a change in the structure of the plasma-polymerized layer with annealing, as shown in Figure 11, that the decrease in the absorbance reduction became larger compared to that in $\mathrm{C}(\mathrm{Ti}-\mathrm{C}) / \mathrm{Ti}$. Therefore the decrease in the vis activity af-

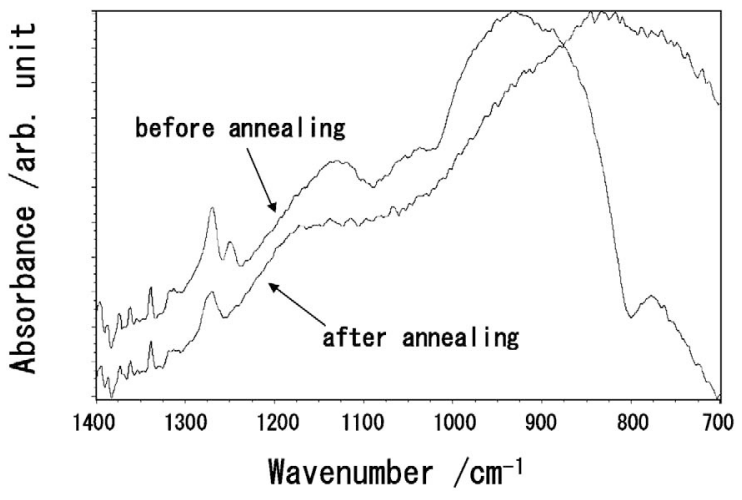

Fig. 11 Infrared spectra of the surface of plasma-polymerized $\mathrm{TiO}_{2}$ particles before and after annealing in air at $673 \mathrm{~K}$ for 60 min. Plasma polymerization time, $30 \mathrm{~min}$. 
ter the annealing would be originated from the decrease in the amount of carbon doping and the formation of dense structure in the plasma-polymerized layer after the annealing.

\section{Conclusion}

Plasma-polymerized thin layer of octamethylcyclotetrasiloxane on $\mathrm{TiO}_{2}$ particles has silica- and siliconcarbide-like structure which is stable to the photocatalytic activity of the particles. The plasma-polymerized $\mathrm{TiO}_{2}$ particles exhibit vis activity. The carbon doping which is confirmed by the appearance of $\mathrm{C}_{1 \mathrm{~s}}$ peak around $282 \mathrm{eV}$ in the plasma-polymerized particles is realized with the plasma polymerization. The amount of carbon doping and the vis activity are decreased by annealing at $673 \mathrm{~K}$, but are maintained to a certain extent.

\section{Acknowledgment}

This work was supported in part by a Grant-in-Aid for Scientific Research on Priority Area (417) from the Ministry of Education, Culture, Sports, Science and Technology (MEXT) of the Japanese Government.

\section{References}

1) K. Takeuchi, I. Nakamura, O. Matsumoto, S. Sugihara, M. Ando and T. Ihara: Chem. Lett., 29 (2000) 1354.

2) T. Ihara, M. Miyoshi, M. Ando, S. Sugihara and Y. Iriyama: J. Mater. Sci., 36 (2001) 4201.

3) R. Asahi, T. Morikawa, K. Aoki and Y. Taga: Science, 293 (2001) 269.

4) T. Morikawa, R. Asahi, T. Ohwaki, K. Aoki and Y. Taga: Jpn. J. Appl. Phys., 40 (2001) L561.

5) H. Irie, Y. Watanabe and K. Hashimoto: J. Phys. Chem. B, 107 (2003) 5483.

6) K. Yamada, H. Nakamura, S. Matsushima, H. Yamane, T. Haishi and K. Kumada: C. R. Chimie, 9 (2006) 788.

7) T. Ohno, T. Mitsui and M. Matsumura: Chem. Lett., 32 (2003) 364.

8) H. Irie, Y. Watanabe and K. Hashimoto: Chem. Lett., 32 (2003) 772 .

9) T. Ohno, T. Tsubota, K. Nakajima and Z. Miyamoto: Chem. Lett., 33 (2004) 750.

10) S. Iwamoto, W. Tanakulrungsank, M. Inoue, K. Kagawa and P. Praserthdam: J. Mater. Sci., 19 (2000) 1439.

11) H. Ozaki, S. Iwamoto and M. Inoue: Chem. Lett. 34 (2005) 1082.

12) H. Yasuda: Plasma Polymerization (Academic Press, Orlando, 1985) p. 52. 